\title{
Planning ESKD treatment: a plea for a stepwise person-centered approach including conservative care
}

\author{
Helena O. Sá1,2,3, Raymond Vanholder ${ }^{4}$ \\ ${ }^{1}$ Department of Nephrology, Centro Hospitalar e Universitario de Coimbra EPE, Portugal \\ 2 University Clinic of Nephrology, Faculty of Medicine, University of Coimbra, Portugal \\ ${ }^{3}$ Ex-President (2008-18) of the Portuguese National Commission for Monitoring of Dialysis (National Health Board), National Health Ministry, Portugal \\ ${ }^{4}$ Nephrology Section, Department of Internal Medicine, Ghent University Hospital, Gent, Belgium and European Kidney Health Alliance, Brussels, Belgium
}

\section{ABSTRACT}

A paradigm shift in the treatment of end-stage kidney disease (ESKD) is urgently needed. New ESKD policies should include integrated and person-centered care that focuses on the individual's preferences, needs, and values for health care. Based on the example of Portugal, a country with a very high number of prevalent in-center hemodialysis patients, the authors reflect on the past and present of ESKD treatment worldwide, trying to summarize the conceptual changes in the efficiency and equity of ESKD treatment. An optimal approach in ESKD management should consider all options for renal replacement therapy, including a comprehensive conservative approach, of which the incidence and prevalence should be reported on a regular basis for each country and for Europe. An active holistic care to patients with ESKD suffering from severe illness or near the end of life, without dialysis or kidney transplant, is still frequently ignored as an option. In cases of frail or very old individuals or in those with multiple co-morbidities or in poor physical condition, conservative treatment should be considered as a firstline option. A proposal of ESKD treatment following the model of classification of CKD is presented. Up-to-date regulations from national health authorities are needed, especially on the priority policy of supportive/palliative care in non-malignant disease, including ESKD.

Keywords: End-stage kidney disease, conservative management, dialysis, integrated person-centered care

\section{INTRODUCTION}

\section{Time present and time past}

Are both perhaps present in time future,

And time future contained in time past.

If all time is eternally present

All time is unredeemable

\section{In Four Quartets, T.S. Eliot}

The development of dialysis and kidney transplantation were important milestones of medicine of the past century. Thanks to scientific inquisitiveness, persistence and the humanism of giants such as the 2002 Albert Lasker Award for Clinical Medical Research winners Willem J. Kolff and Belding H. Scribner and 1990 Nobel Prize winner Joseph Murray, the most severe stage of chronic kidney disease (G5 CKD or End-Stage Kidney Disease) ceased to be fatal and became treatable, prolonging the lives of millions of patients ${ }^{1}$.

If we are to continue improving the survival rate and quality of life of chronic renal disease patients, their families and caregivers, we might borrow from T.S. Eliot, who wrote that time present and time past (in our case present and past end-stage kidney disease (ESKD) treatment) constraints must be taken into account in future strategy, to avoid the risk of significant beneficial achievements being "unredeemable". Indeed, planning the future based on the present and past results of dialysis and kidney transplantation implies changing from a disease-centered or patient-centered treatment, to personcentered care ${ }^{2}$. One of the main differences between person-centered and patient-centered is a focus on the individual's preferences, needs, and values for health care.

In developed countries, ESKD is a major cost driver for health-care systems, with the annual growth of dialysis programs ranging between $6 \%$ and $12 \%$ over the past two decades, while the prevalence is still continuing to grow, particularly in developing countries ${ }^{3}$. Projecting ESKD incidence and prevalence in the United States through 2030, McCullough et al. concluded that the burden of ESKD will continue increasing (between 11-18\%) due to demographic, clinical, and lifestyle shifts in the population and improvements in renal replacement therapy (RRT) ${ }^{4}$. Portugal has one of the highest levels of incidence and prevalence of (treated) ESKD in the world, causing a significant disruption in the lives of chronic renal patients and the consumption of a substantial share of public health expenditure ${ }^{5}$. In Portugal, the incidence and prevalence of treated ESKD ( $D$ or T) keeps increasing each year, as demonstrated by the last data report of the Portuguese Society of Nephrology (PSN) registry related to 2018: the incidence rate was 256 per million people (pmp) and prevalence $2014 \mathrm{pmp}^{6}$. In this article, we reflect on potential solutions to this problem, whereby our knowledge of the Portuguese model is used as an 
example, because of these prevalence values, which are among the highest in Europe.

Several factors could explain the high incidence and prevalence of treated ESKD in Portugal, ranging from the poor control of risk factors, the ageing of the population (in 2017 life expectancy in Portugal increased to 81.6 years), late referral to nephrologists, cultural and social behavior of the general population with poor perception of their health status, universal and unrestricted admission to dialysis and, finally, a good network of dialysis units throughout the entire country, with treatments and transport all covered by the National Health System (NHS) budget.

In countries such as Portugal, a paradigm shift in the treatment of ESKD is needed. In 2015, dialysis-treated ESKD patients, corresponding to $0.1 \%$ of the Portuguese population, consumed $1.7 \%$ of global health care costs (not including transport costs) ${ }^{7}$. This disproportion is in parallel to what has been reported in the United States where ESKD beneficiaries compose $<1 \%$ of the Medicare population but correspond to $7.2 \%$ of total Medicare fee-for-service spending 5 .

To change these figures, more commitment of all involved parties (doctors, nurses, providers, health ministry, society, renal patients) is needed and it is desirable that the focus on dialysis per se is abandoned. G5 CKD patients are increasingly complex and many of them do not conform to the standard clinical outcomes and quality indicators in dialysis.

The questions are: will we still remain focused on the technological imperative and leave issues such as the start of and withdrawal from dialysis to ethics committees? Will we agree to weigh the economic and financial consequences of G5 CKD treatment in a responsible way, which means balancing the effectiveness and equity of health interventions in this specific area of medicine? Resources available for healthcare are not unlimited and should be wisely used and continuously evaluated. Medical tradition emphasizes giving the best care that is technically possible ${ }^{8}$. Reflection on the limitations for dialysis treatment nowadays, compared to the past, would help in planning the most suitable policies for the future. G5 CKD is a severe illness, especially in elderly and disabled people with several co-morbidities. Palliative care, defined generically as the active holistic care of individuals across all ages with serious health-related suffering due to severe illness, and especially of those near the end of life, is likely to be the most appropriate solution for some ESKD patients ${ }^{9}$, as it aims at improving the quality of life of patients, their families and their caregivers.

\section{LIMITATIONS FOR INITIATING DIALYSIS IN THE PAST}

The development of the artificial replacement of human organs has given rise to a wide range of ethical problems that are among the most thoroughly discussed issues in medical ethics. They are, indeed, associated with the birth of the discipline of bioethics ${ }^{10}$. As highlighted, and elegantly summarized by BH Scribner in 1964, several moral and ethical problems that came up in relation to the use of artificial organs, such as hemodialysis, played a major role in therapeutic decision-making in the early days of treatment: patient selection, overt termination of treatment and, finally, the exclusive prolonging of life without quality or dignity ${ }^{11}$. At the beginning of dialysis treatment, the matter of patient selection was a general problem. For example, in the United States in 1964, there had been no more than 50-100 patients transplanted or on chronic dialysis over the 5 preceding years, in contrast to an estimated 10,000 or more people who died for lack of these treatments ${ }^{11}$. The selection of patients was the responsibility of a Committee called the "God Committee" whose members in Seattle were kept anonymous and met periodically to determine which patients could receive treatment at the kidney center ${ }^{12}$. In Portugal, between 1966 and 1975, only the age groups between 15 and 45 years old, which excluded children, were covered; cases in which renal failure was due to systemic disease, such as lupus erythematosus or multiple myeloma, were not considered until much later. The great obstacles to treatment were the unbearable costs and in the first years it was only possible to start and maintain dialysis treatment thanks to the Gulbenkian Foundation and some well-off private entities ${ }^{13}$.

Since the mid-1970s, in countries like Portugal and the United States, dialysis treatment has been fully supported by governmental authorities, with a significant growth in the number of patients starting dialysis, specifically older people, the unavoidable consequence. In fact, between 1970 and 1990, dialysis as a whole became freely accessible while the technique per se became more complex, subject to permanent changes, but also progressively less invasive and risky. To the extent health care procedures improve the associated risk, clinical choice about the desirability of its utilization tends to be neglected ${ }^{14}$. There is a consumer demand and an ethical pressure to offer these treatments, even to those who might not really benefit, such as patients at very advanced age or with a lot of co-morbidities. Contributing to this attitude was the "paternalistic" doctor-patient relationship typical of medical practice in the last decades of the second millennium.

\section{LIMITATIONS FOR INITIATING DIALYSIS AT PRESENT}

Access to RRT is restricted in many countries, even today. An estimated 2.6 million people worldwide were treated for ESKD in 2010, and one to three times that number might have died because they reached ESKD but RRT was declined or could not be accessed ${ }^{15}$. Recent estimates have suggested that 2.3 to 3.2 million people die annually because of an inability to access dialysis or to continue their treatment $^{16}$. Due to access restrictions worldwide, the global country prevalence of dialysis ranges from 0.1 (or zero) to more than 1200 $\mathrm{pmp}^{15}$. Thus, we must conclude that conservative care is, globally, the modality most used for treatment of CKD5, although in most of these cases, this approach is imposed by economic, social and logistic conditions, rather than by deliberate choice. Worldwide, the prevalence of patients receiving RRT in each country is directly related to the gross domestic product (GDP). However, even among countries with similar per capita incomes and health care expenditures per year, there are differences in the availability of life-sustaining therapies such as RRT, which might be associated with different medical and social utility criteria ${ }^{17}$. 
Portugal, a by European standards lower range high-income country $\left(19,930\right.$ USD per capita in $\left.2017^{18}\right)$, has one of the highest levels of prevalence of RRT in the world. The population on dialysis in the country has progressively become older (median age 68 years in $2018)^{6}$. Due to advances in health care assistance in the country, it has been possible to achieve universal access to RRT. Portugal was the first European country to introduce a model of bundled dialysis reimbursement, the "comprehensive price payment" per patient per week, covering all HD services and products, drugs, laboratory services, and associated complementary tests. This new reimbursement scheme is quality driven and linked to the fulfillment of performance indicators and outcomes ${ }^{19}$. A fairly high rate of kidney transplant (KT) receptors among patients on RRT (between 2016 and 2018, 36 to 37\% RRT patients were living with a functioning graft) is an encouraging quality indicator ${ }^{5,20}$. However, Portugal presents a declining prevalence of patients on home dialysis, including peritoneal dialysis (PD), compared to other European countries, Australia and Canada (6\% of dialysis patients in Portugal in 2018 were treated by PD) $)^{5}$. Furthermore, in this country, we still do not have a conservative ESKD care registry, and we do not really know how many patients, at present, initiate or receive this kind of treatment. It is commonly agreed that for elderly patients and those with multiple medical problems besides those with terminal illness, transplantation but also dialysis may confer no benefit, but rather may significantly harm the patient's quality of life ${ }^{21-24}$. It is therefore urgent to improve conservative care resources and facilities and reserve dialysis for those who might really benefit. Brown et al. ${ }^{25}$ state that perhaps the most difficult decision faced by nephrologists today is whether their old and complex patients with advanced CKD are or are not likely to benefit from dialysis. It is desirable to focus on integrated care in ESKD rather than mainly or solely focusing on dialysis. For this to become a routine attitude, we may need to improve doctor and nursing skills in bioethics and palliative care, especially with regard to specialty programs in this area. There is also a contemporary need to develop educative initiatives to increase population health literacy towards palliative medicine. This currently lags behind curative medicine.

Despite technological advances in dialysis treatment, the unadjusted annual mortality of patients with ESKD treated by hemodialysis continues to vary between 14 and $18 \%$ (Portugal and the United States respectively, 2018) ${ }^{5,6}$. Global mortality in the first 90 days of hemodialysis treatment was $4.78 \%$ in $2018^{6}$. Mortality is comprehensively higher in the elderly and those with multiple co-morbidities. In Portugal, data from the National Commission for Monitoring of Dialysis (NCMD) based on a national online application (Plataforma IRC-GID ${ }^{26}$ ) which is directly connected with dialysis units and allows the processing of administrative and clinical data, showed an annual mortality of $38 \%$ for hemodialysis patients between 70 and 80 years old and $55 \%$ for patients over 80 years old (period of analysis of 7 years, between 1 January 2010 and 31 December 2016) ${ }^{27}$. In Portugal, the annual mortality associated to PD treatment is significantly lower than that of hemodialysis but the median age of PD patients is also thirteen years lower than that of hemodialysis patients (annual PD mortality $5 \%$, and median age 55 years in 2018 compared to 68 in hemodialysis) ${ }^{6}$. Data and experience available at this moment teach us that PD is overall a successful first choice regarding survival, depurative efficacy, infectious risk, outcomes after a future kidney transplantation, quality of life and cost-effectiveness of therapy. For the particular ESKD patients suffering from diabetes mellitus and cardiovascular disease such as coronary heart disease, the choice of PD deserves a special ponderation of risks and benefits, as these two co-morbidities may have a more negative impact on the survival of PD patients than hemodialysis patients ${ }^{28}$. As stated by Vanholder et a ${ }^{29}$, applying one reimbursement rate for all methods of dialysis, as in Portugal, the USA and some regions of Canada, could contribute to the widespread use of home-based therapies such as PD. However, in Portugal, the prevalence of an ESKD population with increasing age and frailty and no assisted peritoneal dialysis program supported by Portuguese National Health Service (NHS), could explain the lower proportion of patients treated by PD.

At the present time, we seek to achieve a medical practice with high standards of quality. We have at our disposal safe equipment and procedures of life-extending technologies combined with trained skilled human resources in dialysis and transplant areas. However, although we are seeing a significant evolution of health care systems, we are still not developing up-to-date bioethical skills to improve contact with patients, caregivers and families. The doctor-patient relationship still remains, at present, fundamentally informative, almost "commercial". Since the beginning of the millennium, but more prominently in the last decade, dialysis professionals have begun to recognize the overtreatment of kidney failure with dialysis or the too high frequency of deviations from the principles of person-centered care. We ought to learn and take a step towards a shared decisionmaking process facilitating discharge or withdrawal of dialysis in those patients whose condition does not warrant sufficient quality of life on dialysis ${ }^{30,31}$. The doctor-patient relationship needs to change towards an interpretative one, respecting the principle of consideration of patient preferences and values. Those are the steps needed to allow shared decision-making ${ }^{32}$. This process also necessitates a well-conceived education program, offering to the patient and his/ her family information on all available therapeutic options with their pros and cons, in order to enable a well-informed choice of treatment, and care should be taken that the patient receives this choice, unless clinically contraindicated.

\section{LIMITATIONS FOR INITIATING DIALYSIS IN THE FUTURE}

For the future, a person-centered approach to the treatment of ESKD is increasingly needed ${ }^{33,34}$. Shared decision-making, also implying the need to discuss goals and prognosis early in the course of illness, is the ideal model for complex medical decisions $9,35,36$. The way to reach this aim will be long and arduous, as some issues involved in this kind of patient care are associated with medical and societal culture. But, without any doubt, offering a fair chance to palliative and curative care is currently the only way to go for good medical practice in ESKD. Critical decisions to initiate or continue dialysis treatment should be viewed with the simultaneous consideration of the option of palliative care as a valid alternative ${ }^{37}$. During this process and as early as possible, nephrologists and dialysis nurses can be assisted by or collaborate with palliative care clinicians and nurses. The systematic incorporation of geriatric assessment supported by

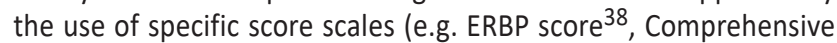
Geriatric Assessment (CGA) mode ${ }^{39}$ ) should be integrated into routine 
analysis of the frailty syndrome ${ }^{40}$. The entire renal team would benefit from this collaborative work and more importantly, the renal patient would receive helpful, outstanding palliative care both before dialysis, as well as when dialysis is arrested 41,42 .

We propose an integrated person-centered care approach for ESKD (G5 CKD), based on advance care planning, prognostication and shared decision-making as represented in Fig. 1 (following the model of classification of CKD, according to international guidelines) ${ }^{30,43}$.

There is an urgency for integrated care in G5 CKD, and to accomplish this there is a need to make different care entities available, enabling the different needs of patients through all levels of illness severity to be satisfied (Fig. 1). In the United States, to face this challenge, programs such as Centers for Medicare \& Medicaid Services' Comprehensive ESKD Care Model were created, which has led to the ESKD Seamless Care Organizations (ESCOs). In ESCOs, dialysis clinics, nephrologists and other providers collaborate to coordinate care for beneficiaries within their network ${ }^{45}$. Some ESCOs include end of life and palliative care organizations. The most important advantage of these new structures is that the patient and his needs play a central role in the health care environment. Procedures and disease-focused interventions are reduced to a minimum and there is an incentive to deliver the optimal therapeutic option for the ESKD patient, including home dialysis, palliative care services and even end-of-life treatment, if necessary ${ }^{46,47}$. In ESCOs there is a care coordinator to facilitate communication between the primary physician, nephrologist and other physicians, including both dialysis access specialists and palliative care specialists, hospital-based clinicians, home care providers and when appropriate, palliative care providers ${ }^{48}$. In the first year of its application (October 1, 2015 through December 31, 2016), the Comprehensive
ESKD Care Model showed fewer hospitalizations and a decrease in overall costs of ESCO beneficiaries with ESKD compared to those who received services at matched dialysis facilities ${ }^{49}$. The creation of a completely different and stepwise model of care for advanced kidney disease is both wise and rational. In stage $4 \mathrm{~b}$ of the integrated care concept for ESKD (Figure 1), conservative kidney management and palliative care should allow the control of uremic symptoms without the need for renal replacement therapy ${ }^{50}$. As conservative care is the provision of adequate palliative care that results in an optimal comfort to the patient, there is an imperious need to monitor these patients tightly.

Dialysis withdrawal is the second or third leading cause of death in patients with ESKD in North America and Australia ${ }^{5}$. It is the responsibility of nephrologists to make suggestions about withholding or withdrawing dialysis ${ }^{51}$. Withdrawal from maintenance hemodialysis has become more common because of high disease and treatment burden, but in most cases the decision comes late and palliative care services are not used. It is, however, difficult to compare data because of differences in definition of withdrawal ${ }^{52}$. In a recent publication, Chen et al. ${ }^{53}$ found that in a population of 1226 incident hemodialysis patients (from 2001 to 2013) in the US, with follow-up through 2015, withdrawal from dialysis was dramatically high (49\%) while after withdrawal, median time to death was only 7 days. This was twice as high as the figures reported by the last USRDS report, where the percentages for patients having discontinued dialysis treatment ranged from $19 \%$ in 2000 to $23 \%$ in $2015^{5}$. It is likely we are facing different kinds of trajectories and causal criteria which justify different coding death preceded by dialysis withdrawal, as highlighted by Murphy et $\mathrm{al}^{52}$. In the near future we all should develop the practice of reporting mortality data across the countries and the units in a more uniform way.

\section{Figure 1}

Schematic presentation of Integrated care in ESKD with different categories (from 1 to 5 , stage 4 divided into 4a and 4b) (Proposal).

\begin{tabular}{|c|c|c|c|}
\hline \multicolumn{4}{|r|}{ Integrated care in ESKD (G5 CKD) } \\
\hline \multicolumn{2}{|c|}{ Phase } & Treatment-specific & Recommendations \\
\hline \multicolumn{2}{|c|}{1} & $\begin{array}{l}\text { Comprehensive conservative } \\
\text { renal care (CRC) }\end{array}$ & $\begin{array}{l}\text { Concluding patient education about ESKD treatment modalities (RRT and CRC); practice shared decision-making. } \\
\text { Postpone starting renal RRT if no symptoms and GFR }>6 \mathrm{ml} / \mathrm{m} / 1,73 \mathrm{~m}^{2} \text { particularly in elderly patients with multiple comorbidities. } \\
\text { If treatment choice is conservative management, progress to stage } 4 \mathrm{~b} \text {. } \\
\text { (Evidence A, Grade of Recommendation I) } \\
\text { KDIGO } 2015^{30} \text {, EBPG } 2011^{44}\end{array}$ \\
\hline \multicolumn{2}{|c|}{2} & Preparing for RRT (D or T) & $\begin{array}{l}\text { Prepare for peritoneal dialysis (PD), hemodialysis (HD) or kidney transplantation (KT). } \\
\text { Provide specific assistance in case of home dialysis modalities, if necessary. }\end{array}$ \\
\hline \multicolumn{2}{|c|}{3} & RRT (D) & Maintenance in RRT (D) in case of positive outcomes. \\
\hline \multirow[t]{2}{*}{4} & $4 a$ & $\begin{array}{l}\text { RRT (D) without benefit - } \\
\text { prepare for Comprehensive } \\
\text { conservative renal care (CRC) }\end{array}$ & $\begin{array}{l}\text { No benefit in survival and impairment in quality of life; non-compliance with Key Performance Indicators used to monitor the quality of } \\
\text { RRT, especially dialysis therapy: consider dialysis withdrawal and communicate information to patients and families, proceeding to refer- } \\
\text { ral for supportive care. } \\
\text { (Evidence B, Grade of Recommendation I) }\end{array}$ \\
\hline & $4 \mathrm{~b}$ & $\begin{array}{l}\text { Comprehensive conservative } \\
\text { renal care (CRC) }\end{array}$ & Supportive/palliative care (symptom-based). \\
\hline \multicolumn{2}{|c|}{5} & $\begin{array}{l}\text { End-of-life care } \\
\text { (survival }<3 \text { months) }\end{array}$ & $\begin{array}{l}\text { At home, hospice or hospital, according to patient life goals and global condition; helping patients die with dignity and their family at } \\
\text { their side. Using full conservative medical management or appropriate dose of dialysis/ultrafiltration, if needed. }\end{array}$ \\
\hline \multicolumn{4}{|c|}{ SKD - End-stage kidney disease or G5 CKD includes patients with kidney failure with and without renal replacement therapy. } \\
\hline
\end{tabular}


More than at present, ESKD treatment should be offered in a more personalized way while allocation of health care resources in this area must enable free access to all categories of treatment (Fig. 1). The national health systems should develop action plans to remove barriers for delivery of true palliative care and end-of-life care, when appropriate, for patients with ESKD. Dialysis technology is complex and a great progress in medicine, but dealing with the complexity of family, social, psychological and medical conditions affecting patients with ESKD is more demanding and time-consuming, in order to offer them the best treatment at each level of severity of the disease ${ }^{41}$. As Fuchs stated more than fifty years ago, the growing demand for medical care should not relieve us from realistically facing the problems of the existing system, and taking the lead in devising ways to improve $i^{8}$. To the best of our knowledge, this will in the coming decades be the only way to provide artificial support to sustain human life, such as with kidney replacement therapy, in an ethical and sustainable way.

\section{Acknowledgement}

About EKHA: EKHA is a common effort by all European key stakeholders in kidney care to propose solutions for the challenges of Chronic Kidney Disease in Europe through effective prevention and a more efficient care pathway intended to facilitate the provision of appropriate and affordable treatment to all Europeans equally, while promoting the highest quality of care. EKHA works on the principle that the issue of kidney health and disease must be considered at European level and that both the European Commission and European Parliament have vital roles to play in assisting national governments with these challenges. EKHA is self-supporting but organizes each year an event related to kidney disease and care in the European Parliament with the support of industry (unrestricted grant). This year's event on kidney transplantation was supported by Amgen, Astellas, Baxter Healthcare, BBraun, CSL Behring, Vifor Pharma.

Disclosure of potential conflicts of interest: none declared

\section{References}

1. 2002 Albert Lasker Award for Clinical Medical Research. J Am Soc Nephrol. 2002 Dec;13(12):302730 .

2. Morton RL, Sellars M. From patient-centered to person-centered care for kidney diseases. Clin J Am Soc Nephrol. 2019 Apr 5;14(4):623-25.

3. Couser WG, Remuzzi G, Mendis S, Tonelli M. The contribution of chronic kidney disease to the global burden of major noncommunicable diseases. Kidney Int. 2011 Dec;80(12):1258-70.

4. McCullough KP, Morgenstern H, Saran R, Herman WH, Robinson BM. Projecting ESKD incidence and prevalence in the United States through 2030. J Am Soc Nephrol.2019 Jan;30(1):127-35.

5. United State Renal Data System. www.usrds.org (accessed February, 2019).

6. http://www.spnefro.pt/tratamento_da_doenca_renal_terminal/2018 (accessed 29 April, 2019).

7. Relatório de Acompanhamento de Actividade - Hemodiálise 2015. http://www2.acss.minsaude.pt/Portals/0/2015.pdf (accessed April, 2019).

8. Fuchs VR. The growing demand for medical care. N Engl J Med. 1968;279:190-5

9. International Association for Hospice and palliative care. Palliative care definition 2018. https:// hospicecare.com/what-we-do/projects/consensus-based-definition-of-palliative-care. (accessed April, 2019).

10. Butler CR, Mehrotra R, Tonelli MR, Lam DY. The evolving ethics of dialysis in the United States: A principlist bioethics Approach. Clin J Am Soc Nephrol. 2016 Apr 7;11(4):704-9.

11. Scribner BH. Ethical problems of using artificial organs to sustain human life. Trans Am Soc Artif Intern Organs. 1964;10:209-12.

12. Alexander S. They decide who lives, who dies: Medical miracle puts a moral burden on a small committee. Life. 1962, pp 102-104, 106, 108, 110, 115, 117, 118, 123, 124, 127.
13. Simões J. Contribuição para a história da Nefrologia em Portugal. Rev Port Nefrol Hipert 2004;18(2):61-70

14. Kaufman SR, Shim JK, Russ AJ. Revisiting the biomedicalization of aging: Clinical trends and ethical challenges. Gerontologist. 2004 Dec;44(6):731-8.

15. Liyanage T, Ninomiya T, Jha V, et al. Worldwide access to treatment for end-stage kidney disease: A systematic review. Lancet. 2015 May 16:385(9981):1975-82.

16. Luyckx VA, Tonelli M, Stanifer JW. The global burden of kidney disease and the sustainable development goals. Bull World Health Organ. 2018 Jun 1;96(6):414-22D.

17. Obrador GT, Rubilar X, Agazzi E, Estefan J. The challenge of providing renal replacement therapy in developing countries: The Latin American perspective. Am J Kidney Dis. 2016 Mar;67(3):499-506

18. Data from World Bank. Last updated: Jul 6, 2018. https://www.google.com/publicdata/ explore?ds=d5bncppjof8f9_\&met_y=ny_gdp_pcap_cd\&hl=en\&dl=en (accessed April 2019)

19. Coelho AP, Sá HO, Diniz JA, Dussault G. The integrated management for renal replacement therapy in Portugal. Hemodial Int. 2014 Jan;18(1):175-84.

20. Vanholder R, Stel VS, Jager KJ at al. How to increase kidney transplant activity throughout European advocacy review by the European Kidney Health Alliance. Nephrol Dial Transplant. 2019 Jan 34 (8): Pages 1254-1261

21. Kurella Tamura M, Covinsky KE, Chertow GM, Yaffe K, Landefeld CS, McCulloch CE. Functional status of elderly adults before and after initiation of dialysis. N Engl J Med. 2009 Oct 15;361(16):1539-47

22. Carson RC, Juszczak M, Davenport A, Burns A. Is maximum conservative management an equivalent treatment option to dialysis for elderly patients with significant comorbid disease? Clin J Am Soc Nephrol. 2009 Oct;4(10):1611-9.

23. Chandna SM, Da Silva-Gane M, Marshall C, Warwicker P, Greenwood RN, Farrington K. Survival of elderly patients with stage 5 CKD: Comparison of conservative management and renal replacement therapy. Nephrol Dial Transplant. 2011 May;26(5):1608-14.

24. O'Connor NR, Kumar P. Conservative management of end-stage kidney disease without dialysis: a systematic review. J Palliat Med. 2012 Feb;15(2):228-35.

25. Brown MA, Collett GK, Josland EA, Foote $C$, Li $\mathrm{Q}$, Brennan FP. CKD in elderly patients managed without dialysis: Survival, symptoms, and quality of life. Clin J Am Soc Nephrol. 2015 Feb 6;10(2):260-8.

26. Insuficiência renal - GID - Gestão integrada da doença. https://gid.min-saude.pt/gid/login. php (accessed February 2019).

27. Almeida E. National Commission for Monitoring of Dialysis (NCMD), Administração Central dos Serviços de Saúde (ACSS) and Direção-Geral da Saúde (National Health Board), 2017 (data not published).

28. Mehrotra R, Devuyst O, Davies SJ, Johnson DW. The current state of peritoneal dialysis. J Am Soc Nephrol. 2016 Nov;27(11):3238-52.

29. Vanholder R, Annemans L, Brown E, Gansevoort R, Gout-Zwart JJ, Lameire N, Morton RL, Oberbauer R, Postma MJ, Tonelli M, Biesen WV, Zoccali C; European Kidney Health Alliance. Reducing the costs of chronic kidney disease while delivering quality health care: a call to action. Nat Rev Nephrol. 2017 Jul;13(7):393-409.

30. Davison SN, Levin A, Moss AH et al. Kidney disease: Improving global outcomes. Executive summary of the KDIGO Controversies Conference on Supportive Care in Chronic Kidney Disease: Developing a roadmap to improving quality care. Kidney Int. 2015 Sep;88(3):447-59.

31. Renal Physicians Association: Shared Decision-Making in the Appropriate Initiation and Withdrawal from Dialysis, 2nd Ed., Rockville, MD, Renal Physicians Association, 2010.

32. Ethical Challenges and the Role of Palliative Care in Kidney Disease Michael J. Germain, MD, and Lewis M. Cohen, MD. Chronic Kidney Disease, Dialysis, and Transplantation, Fourth Edition, 2019.

33. O'Hare AM, Armistead N, Schrag WL, Diamond L, Moss AH. Patient-centered care: An opportunity to accomplish the "Three Aims" of the National Quality Strategy in the Medicare ESKD program. Clin J Am Soc Nephrol. 2014 Dec 5;9(12):2189-94.

34. Barry MJ, Edgman-Levitan S. Shared decision making-pinnacle of patient-centered care. N Engl J Med. 2012 Mar 1;366(9):780-1.

35. Williams AW, Dwyer AC, Eddy AA et al. American Society of Nephrology Quality, and Patient Safety Task Force. Critical and honest conversations: The evidence behind the "Choosing Wisely" campaign recommendations by the American Society of Nephrology. Clin J Am Soc Nephrol. 2012 Oct;7(10):1664-72

36. Perry E, Joy S, Swartz R. Staying the course: Through end of life in ESKD. J Am Soc Nephrol. 2019 Feb 19. pii: ASN.2019010020

37. Carson R. Deny dialysis or "D-NI" dialysis? The case for "do not initiate; do not ignore" orders. Clin J Am Soc Nephrol. 2012 Dec;7(12):1924-6.

38. Farrington K, Covic A, Aucella F at al. ERBP guideline development group. Clinical Practice Guideline on management of older patients with chronic kidney disease stage $3 \mathrm{~b}$ or higher (eGFR<45 $\mathrm{mL} / \mathrm{min} / 1.73 \mathrm{~m} 2$ ). Nephrol Dial Transplant. 2016 Nov;31(suppl 2):ii1-ii66.

39. Parker SG, McLeod A, McCue P, Phelps K, Bardsley M, Roberts HC, Conroy SP. New horizons in comprehensive geriatric assessment. Age Ageing. 2017 Sep 1;46(5):713-21. doi: 10.1093/ageing/ afx104. Review.

40. Brown EA, Farrington K. Geriatric Assessment in Advanced Kidney Disease. Clin J Am Soc Nephrol. 2019 May 22. pii: CJN.14771218.

41. Kurella Tamura M, Meier DE. Five policies to promote palliative care for patients with ESKD. Clin J Am Soc Nephrol. 2013. Oct;8(10):1783-90.

42. Murtagh FE, Marsh JE, Donohoe P, Ekbal NJ, Sheerin NS, Harris FE. Dialysis or not? A comparative survival study of patients over 75 years with chronic kidney disease stage 5 . Nephrol Dial Transplant. 2007 Jul;22(7):1955-62.

43. Kidney Disease: Improving Global Outcomes (KDIGO) CKD Work Group. KDIGO 2012 Clinical Practice Guideline for the Evaluation and Management of Chronic Kidney Disease. Kidney International 2013:3:1-150 
44. European best practice guidelines on haemodialysis. 22(2), May 2007.

45. Grubbs V. ESKD and hospice care in the United States: Are dialysis patients welcome? Am J Kidney Dis. 2018 Sep;72(3):429-32.

46. Murphy E, Germain MJ, Murtagh F. Palliative nephrology: time for new insights. Am J Kidney Dis. 2017 Nov; 70(5):593-5

47. Johnson DS, Meyer KB. Leading integrated kidney care entities of the future. Adv Chronic Kidney Dis. 2018 Nov;25(6):523-9.

48. Johnson DS, Meyer KB. Delaying and averting dialysis treatment: Patient protection or moral hazard? Am J Kidney Dis. 2018 Aug;72(2):251-4.

49. Comprehensive End-Stage Renal Disease Care (CEC) Model Performance Year 1 Annual Evaluation Report. https://innovation.cms.gov/Files/reports/cec-annrpt-py1.pdf. (accessed 29 may 2019).

50. Davison SN, Tupala B, Wasylynuk BA, Siu V, Sinnarajah A, Triscott J. Recommendations for the care of patients receiving conservative kidney management: focus on management of CKD and symptoms. Clin J Am Soc Nephrol. 2019 Apr 5;14(4):626-34.

51. McDonald SP. Australia and New Zealand dialysis and transplant registry. Kidney Int Suppl (2011). 2015 Jun;5(1):39-44
52. Murphy E, Germain MJ, Cairns H, Higginson IJ, Murtagh FE. International variation in classification of dialysis withdrawal: A systematic review. Nephrol Dial Transplant. 2014 Mar;29(3):625-35. 53. Chen JC, Thorsteinsdottir B, Vaughan LE et al. End of life, withdrawal, and palliative care utilization among patients receiving maintenance haemodialysis therapy. Clin J Am Soc Nephrol. 2018 Aug 7;13(8):1172-9.

\section{Correspondence to:}

Helena O. Sá, MD, PhD

Department of Nephrology, Centro Hospitalar e Universitario de Coimbra EPE, Portugal

E-mail: helena.oliveirasa@sapo.pt 